\title{
Klasik Batı Müziği Bağlamında Müzikal Göstergebilimde Temel Birim Sorunsalı
}

Öz: Anlam bilimi açısından temel birim sorunsalı temelde bir dilbilim sorunsalı olmasına rağmen, yirminci yüzyılda diğer birçok alan gibi müzik estetiği ve müzikal göstergebilim alanları için de bir tartışma konusu olagelmiştir. Ferdinand de Saussure ve Charles Peirce öncülüğünde gelişen göstergebilim, dil modelini sosyal bilimlerin psikoloji, antropoloji, felsefe, edebiyat bilimi, anlatı bilim gibi alanlarına ve resim, sinema, tiyatro ve müzik gibi sanat alanlarına uygulanmıștır. Ancak bir gösterge sistemi olarak dilde, gösterenin temel biriminin fonem/sesbirim olduğu, gösterilenin temel biriminin ise monemöne sürülebilecekken, görece daha yeni bir alan olan müzikal göstergebilim söz konusu olduğunda böylesi bir birimin varlığı halen tartışmalı bir konudur. Müzikal göstergebilim alanında şimdiye kadar yapılan öncü çalışmalar bu sorunsalı çeşitli bakımlardan ele almış, ancak tartışma Klasik Batı Müziği ekseninde sürdürülmesine rağmen temel birim sorunsalı için tatmin edici bir uzlaşı sağlanamamıştır. Bu çalışmada müzikal göstergebilimde temel birim sorunsalı temel göstergebilim kuramları açısından sorgulanacak ve müzikal göstergebilimde olası bir temel birimin varlığına dair bir tartışma yürütülecektir. Bu bağlamda öncelikle F. de Saussure, C. Peirce ve R. Barthes gibi göstergebilim alanının öncülerinin göstergebilim kuramlarınakısaca değinilecek ve bu kuramların olası bir uygulamasının müzikal göstergebilime sağlayabileceği katkılar J. Molino, M. Baroni, J. J. Nattiez ve N. Ruwet gibi müzikal göstergebilim alanında çalışan uzmanların görüşlerine başvurularak soruşturulacaktır. Tartışmayı takiben, N. Ruwet'nin "tepeden dibe doğru" ya da "dipten tepeye doğru" olarak adlandırdığı iki ayrı yolla, söz konusu sorunsala yönelik alternatif bir fenomenolojik uygulama önerilecektir. Öte yandan, eldeki mevcut kısıtlı literatür, tartışmayı Klasik Batı Müziği ekseninde sürdürmüş olduğundan, çalışmanın evrensel kümesinin Klasik Batı Müziği olarak kısıtlanması tercih edilmiştir. Anahtar Kelimeler: Gösteren, Gösterilen, Eklemlenme, Tonalite, Nota. 


\title{
The Question of Basic Unit in Musical Semiotics in the Context of Classical Western Music
}

\begin{abstract}
Although the question of basic unit is a question of linguistics in principle, it has been a question of musical aesthetics and of musical semiotics in twentieth century likewise of many other disciplines. Developed under the pioneering roles of Ferdinand de Saussure and Charles Peirce, semiotic studies have applied the language model to the disciplines of social sciences such as psychology, anthropology, philosophy, literary science, narratology, and artistic disciplines such as painting, cinema, theater and music.While it could be argued that the basic unit of a signifier is phoneme or of a sign is moneme, the question of basic unit is still an arguable question in musical semiotics, a relative new discipline. Pioneering studies in musical semiotics have dealt with this problematic in various aspects, but although the discussion has continued on the axis of Classical Western Music, a satisfactory consensus has not been achieved for the basic unit problematic.In this paper, the question of basic unit in musical semiotics will be examined in regard to the major semiotics theories and an inquiry on the existence of a possible basic unit in music will be performed. In this context, a brief summary of the semiotics theories of F. de Saussure, C. Peirce and Barthes; and the possible contribution of a possible application of these theories to the musical semiotics will be discussed by referring to J. Molino, M. Baroni, J. J. Nattiez and N. Ruwet. Following the discussion, an alternative phenomenological application to the question will be suggested by using the two ways as N. Ruwet names "from top to bottom" and "from bottom to top". On the other hand, since the limited literature at hand has continued the discussion on the axis of Classical Western Music, the universal set of this study was intentionally limited to Classical Western Music. Keywords: Signifier, Signified, Articulation, Tonality, Note.
\end{abstract}

\section{Giriş}

Yirminci yüzyılda birbirinden tamamen bağımsız iki kuramcl, C. Peirce ve F. de Saussure tarafından ayrı ayrı kavramsallaştırılmış olan iki ayrı göstergebilim kuramının sosyal bilimlere önemli katkıları olmuştur. Her iki kuram da temsil ilişkisinin içsel mantığını açıklamaya aday olmak yönünden ortaklaşmaktadır ve sonuç olarak yirminci yüzyılın başlarından itibaren dilbilimle ilgili modelin birçok farklı alanda uygulanması girişimlerini doğurmuştur (İlim 2019: 58; Fıșkın 2018: 293). Rusya'da Biçimciler ve Bahtin Çevresi, Fransa'da R. Barthes ve C. LeviStrauss, İtalya'da ise Umberto Eco tarafından öncülüğü yapılan bu uygulamalarda göstergebilim, edebiyat, anlatıbilim, resim, sinema, antropoloji, moda ve mimari gibi birçok alana uyarlanarak bu alanların özgün göstergebilim modelleri geliştirilmiştir. 
Müzikal göstergebilim alanı ise 1960'lardan başlayarak, görece daha geç bir dönemde ortaya çıkmıştır. Bu alanda yapılan öncü çalışmalar Nicolas Ruwet, Jean Molino, J. J. Nattiez ve Mario Baroni tarafından gerçekleştirilmiş. Ruwet'nin bu alandaki ilk çalışmalardan biri sayılabilecek 1966 tarihli Methodes D'analyse En Musicologie (Ruwet 1987: 11-36) başlıklı makalesi yöntem tartışmalarına, tanımlara ve temel ayrımlara odaklanan oldukça yetkin bir çalışma olsa da, Molino ve Nattiez'in 1970'li yıllarda takip eden çalışmaları temel varsayımları sorgulamaktan ve sistematik olmaktan büyük oranda uzaktır. Baroni'nin 1981 tarihli Sulla Nozionedi Grammatica Musicale (Baroni 1983: 175-208) başlıklı makalesi bu sorunları açıkça tespit eder. Baroni bu çalışmasında bilgisayar bilimleri ve istatistik gibi alanlarla ilişkilendirilen zengin tartışmalar sunmuş olsa da, temel birim sorunsalı burada da halen güncelliğini korumaktadır.

Günümüzde örneğin $440 \mathrm{HZ}$ frekansı "La / A" sesi için çoğunlukla evrensel bir sabit kabul edilmekte ve nesnel olarak tespit edilebilmektedir. Yine benzer sabitler kullanılarak hazırlanmış olan yazılımlar müzik endüstrisinin ihtiyaç duyduğu, yaratıcılık gerektirdiğine inanılan birçok işlemi yetkin bir şekilde gerçekleştirebilmektedir. Ancak anlamlandırma edimi söz konusu olduğunda halen açık bir soru ile karşı karşıya olduğumuzu kabul etmemiz gerekir: "Müzik dediğimiz nedir?" ya da diğer bir ifadeyle "Ne ile karşılaştığımız andan itibaren karşımızdakinin 'müzik' olduğunu söyleyebiliriz?” Bu soru bizi kaçınılmaz olarak temel birim sorunsalına geri götürür. Sorunsalın ele alınmasında olası yollardan biri, onu aktüel işitme deneyimine ve genel olarak deneye başvurmaksızın, fenomenolojik bir yolla araştırmaktır. Bu çalışmada söz konusu yöntemle temel birim sorunsalı ele alınacak ve özel olarak gösteren ile gösterilen arasındaki eklemlenme olgusu aranacaktır. Bu bakımdan, uzmanların görüşlerini tartıştıktan sonra kullanılacak olan yöntem, Ruwet'nin“tepeden dibe doğru” ya da "dipten tepeye doğru" olarak adlandırdığı iki ayrı yolla, müzikal göstergenin varlığından söz edebilmemiz için gerekli olan eklemlenme olgusunun ortaya çıktığı ve tam aksine, eklemlenme olgusunu yitirdiğimiz iki deneyim üzerine odaklanmak 
olacaktır. Diğer bir deyişle, her iki yol ayrı ayrı kullanılarak müzikal bir gösteren ile müzikal bir gösterilenin ilk kez eklemlendiği ve eklemlenmenin ortadan kalktığı iki ayrı uğrak fenomenolojik bir yolla incelenecektir.

Görece yeni bir alan olan müzikal göstergebilim 1960'lardan başlayarak Klasik Batı Müziği bağlamında tartışılagelmiştir. Tartışmanın diğer müzik geleneklerini ve müzik tarzlarını kapsayacak biçimde genişletilmesi alanın gelişimi açısından faydalı ve gerekli olabilirse de, bu çalışmanın kapsamı bir uğrak olarak Klasik Batı Müziği ile kısıtlanmıştır. Alanın görece yeni olmasının bir diğer dezavantajı literatür kısıtlılığı olarak kendini göstermektedir. Şimdiye kadar bu alanda yapılan çalışmalar büyük oranda J. Molino, M. Baroni, J. J. Nattiez ve N. Ruwet'ın bu çalışmada adı geçen öncü çalışmalarından ibarettir. Bu nedenle, çalışmamızın kuramsal tartışması, sözü edilen uzmanların görüşleri ile kısıtlanmıştır.

\section{Göstergebilimsel Yaklaşımlar}

C. Peirce göstergenin bir temsil ilişkisi olmasının yanında,temsiliyetinde üç farklı yolla olabileceğini savunmuștur: Benzerlik, işaret etme ve sembol. Bunların ilkinde her iki unsur arasında fiziksel bir bağlantı mevcut olmalıdır ya da fiziksel bir ortaklık bulunmalıdır. İkinci olarak, işaret etmede bir parmağın basitçe yaptığına benzer bir yönlendirme olmalıdır. Üçüncüsünde ise birbirinden ayrı iki şeyin bir uzlaşı ya da anlaşma dolayımıylabir araya gelmesi söz konusudur (Peirce 1986:82; Peirce 1998: 6-9, 67-68, 82-83).

Peirce temsiliyet ilişkisini üçlü bir terminoloji ile açıklar: Buna göre nesne ve gösterge arasında bir "yer tutma" ilişkisi söz konusudur; ancak bir üçüncü unsur, yorumlayan da bu ilişkide anlamın kurucu öğelerinden biri olarak dolayımı sağlar ve söz konusu ilişkiyi dinamik tutar (Peirce 1998: 478; Peirce 1986: 66-68).

Saussure'ün gösterge kuramı ise büyük oranda özgün bir değer kuramına dayanır. Para ve bayrak gibi tipik örneklerde görüleceği üzere, bir kâğıt parçası ya 
da bir bez parçası bir uzlaşım yoluyla yeni bir anlam kazanır. Maddi düzlemi aşan bu süreç sonunda para, malzemesi olan kâğıdın maddi değerini mutlaka aşar ya da bayrağın değeri, malzemesi olan kumaşın değerini mutlaka aşar. Burada değerin kaynağı uzlaşımsallıktır (Saussure 2014: 66, 281; Saussure 1998: 39).

Saussure bu uzlaşımsal bütünü gösterge olarak adlandırır ve onu metodolojik açıdan gösteren ve gösterilen olarak ikiye ayırır. Maddi düzlem ya da göstergedeki maddi töz gösteren olarak, onun uzlaşım yoluyla kazandı̆̆ı kavramsal içerik ise gösterilen olarak isimlendirilir. Gösterenin zorunlu olarak mimetik sürece açlk olması, yani göstergeyi kullanan topluluğun üyelerinin tekrar edilebilir kullanımına elverişli olması, böylece her karşılaşmada tanınabilmesi beklenir. Öte yandan bu iki unsurun, gösteren ve gösterilenin birbiriyle olan birleşiklik olgusunu Saussure bir dilbilim terimi olan eklemlenme/artikülasyon terimi ile imler (Saussure 1998: 164-167).

Tartışmamız açısından Saussure'ün kuramındaki en özgün yönlerden biri, gösteren ile gösterilen arasındaki bağın doğal bir nedene dayanmıyor oluşunun özel olarak altının çizilmiş olmasıdır. Bu iki unsur arasında doğal ve zorunlu bir bağ yoktur; örneğin elma meyvesinin kavramsal içeriğini göstermek için Türkçede "elma” yerine İtalyancadaki gibi "mela" sözcüğü kullanılmış olabilirdi (Saussure 2014: 35; Saussure 1998: 118). Burada bu sözcüğün kendisinin eklemli olduğu kavramsal içerik ile doğal ve zorunlu bir bağı olmaması anlamında, Saussure aradaki bağlantının nedensizlik ilkesine dayandığını ifade eder. Ancak tam da bu nedenden Saussure'ün göstergebilim kuramı"gösterilen öncelikli" bir kuram olması ithamıyla yüzleşmekten kaçamamıştır (Derrida 1994: 31-45).

Saussure'ün dikkat çektiği eklemlenme olgusu, diğer tüm alanların ötesinde, müzik için oldukça özel bir durum sergiler. İdeal olarak müzik, hem bir fizik olayını hem bu olayın işitme ve anlamlandırma sürecini hem de etkinliğin, ürünün ve alımlanmasınınkültürel bağlamını içeren bir estetik disiplindir. Ancak bunun yanında, diğer sanat dallarıyla benzer olmayacak bir şekilde, icra açısından 
müziğin materyali bir madde değil, bir olay olarak karşımıza çıkar; ve nota yazımı söz konusu olduğunda gösteren-gösterilen ilişkisi ikincil bir dolayıma girer: İcra esnasında gösteren işlevi görmesi beklenen ölçülü sesin, nota yazımında gösterilen işlevi görmesi beklenir (Zeren 2010: 2-5). Müzik adının (örneğin MZK gibi) bir başka gösteren ile eklemlenmesi de ilkece mümkündür, ancak bu durumda olgunun kendisinden bir adım daha uzaklaşmış oluruz. Bu durumda artık, Peirce'ın deyimiyle "birbirinden ayrı iki şeyin bir uzlaşı ya da anlaşma dolayımıyla bir araya gelmesi" olarak bir sembol varlığı söz konusudur. Aksine, benzerlik ya da işaret etmede olduğu gibi, nota yazımını da önceleyecek bir yolla icranın kendisine dönerek, müziğin temel bileşenlerinin bir gösteren ile eklemlenişini incelemek gerekecektir.

Peirce ve Saussure'ün ardından göstergebilim, dilbilimsel modelin diğer insan üretim alanlarına uyarlanmasıyla gelişmesini sürdürmüştür. Ancak bekleneceği üzere, temel tartışmalardan biri, göstergebilimin Barthes'ın deyimiyle müzik gibi ikinci dillere nasıl uyarlanacağı olmuştur. Bunun için gerekli olan, göstergebilimin öncelikle kimi pratik sorunlara dair yaygınlaştırılabilir bir metodoloji sahibi olmasıdır. Barthes bu noktada bir anlambilim ihtiyacını açıkça dile getirir. Ona göre, birbirinden oldukça farklı gösterenler kullanan moda, sinema, resim, edebiyat, mimari ve antropoloji gibi alanlarda "dilsel gösterilenin büründüğü biçimlerin sınıflandırması" ve sistemlerin nasıl bölümleneceğinin belirlenmesi gerekir. Diğer bir deyişle, dilbilimsel modelin dil, söz, gösterge, gösteren, gösterilen gibi temel ayrımlarının diğer alanlara nasıl uygulanacağı gibi temel sorunlara gerçekçi yanıtlar aranmalıdır (Barthes 2009: 23-101).

\section{Müzikal Göstergebilime İlişkin Temel Yaklaşımlar}

Bir müzikal analiz sorunu ve özel olarak da müzikal göstergebilim sorunu olarak temel birim problemi ilk kez J. Molino ve N. Ruwet tarafından dile getirilmiştir. Molino’ya göre tonal Batı müziğinde temel birim notadır ve notanın göstergebilimsel varlığı nota yazımının kompozisyon, icra, dinleme süreçlerinde 
garanti altına alınmıştır. Buna ek olarak, müzik kültüründeki yeriyle nota için de aynı şeyi söylemek mümkündür: Enstrümanlardaki perde sabitliği buna örnek gösterilebilir. Ancak yine Molino’yagöre, notanın temel müzikal birim olduğu sonucuna hızlıca varmak yanlıştır; zira nota eş zamanlı olarak hem mutlak bir ses perdesini hem de sanal bir ses aralığını, sanal dereceleri, işlevleri ve ritim taşıyıcı süreleri de imler. Bu durumda birim üç seviyede var olabilir: (1) Nota, (2) hücre ya da motif gibi temel nota grupları ve (3) bunların kombinasyonları. Ancak Molino'ya göre, her durumda esas dikkat çekilmesi gereken nokta şudur ki; dilbilim göstergesi ile kıyaslandığında, müzik notası kendi başına var olamayan bir fenomen taşır. Sözlü gelenekte ya da çağdaş müzikte notanın yokluğu ise aynı sorunu ikinci kez gündeme getirir: Eklemlenme olgusunun, yani müzikal gösteren ile müzikal gösterilenin eklemlenme sürecinin takibi zordur (Molino 1990: 141142).

Molino bu noktada dil-söz ayrımını müzikoloji açısından tesis etmeye yönelik olarak Saussuresonrası tartışmalara odaklanır. Sunmuş olduğu oldukça zengin kuramsal tartışma kimi teknik hatalar içeriyorsa da, Molino bir taksonomi belirlemeye çalışarak dilbilimsel dil-söz ayrımını müzikoloji açısından nereye yerleştireceğimizi belirlemeyi amaçlamaktadır:

[...] Beklenen akustik gösterenin bir gösterileni, bir referansı/göndergesi var mıdır? Hadi ilk yanıtımız bir soru olsun: 'Unicorn', 'tanrı', 'abra kadabra”, 'Fransa' veya 'meditasyon' sözcüklerinin referansı/göndergesi nedir? İkinci olarak, halen bir model olarak ele alınan sözel gösterilen nedir? 'Sandalye' sözcüğünü duyduğumda ya da etrafımdaki insanların konuştuğunu duyduğumda ne düşünürüm? Don Giovanni'nin birkaç ölçüsünü ya da 106 numaralı sonatı duyduğumda ne yaparım? Hissetmek, düş görmek, sohbet etmek, hayal etmek, sindirmek? İtiraf etmeliyiz ki bir sınır çekmek zordur. Quine ile birlikte, günümüzde gösterme/imleme [signification] sorununun felsefede tanrının varlığı sorunu kadar büyük rol oynadığını düşünecek olursak korkmamıza gerek yok. Bunların düşüncenin hangi moduna dahil olduklarını kendimize sormadan evvel müziği, dini ve dili tanımlayalım. (Molino 1990: 126).

Burada sorun, bir müzikal kod ile herhangi bir eylemi gerçekleştirip gerçekleştiremeyeceğimiz değil elbette. Bir kahve sipariş etmeniz için iyi bir füg icrası sunmanız gerekmez; zira müzik, özel bir ikincil işlev kazanmadığı müddetçe 
gündelik eylemlerimiz için kod işlevi görmez. Bir kod, iletişim kurmamıza, hayal etmemize, arzu duymamıza ya da bilgisayarı yönetmemize yarayabilir, ancak sanat alanında eserler için böyle pragmatik işlevler aramamız beklenemez. Her durumda yanıtlamakla mükellef olduğumuz esas sorun, her seferinde aynı gösterengösterilen ilişkisini takip edip edemediğimiz olmalıdır. Bir doğal Do-majör akoru yazıp bunun bir doğal Re-minör akoru olduğunu savunamayacağımıza göre, müziğin yapısal birimleri olan göstergelerin her seferinde takip edilebilir ve tekrar edilebilir olmalarını sistemli bir biçimde açıklayabilmemiz gerekir.

Alanın bir diğer uzmanı M. Baroni Müzikal Dilbilgisi Kavramı başlıklı makalesinde bu gerekliliği oldukça açık ve anlaşılır bir biçimde dile getirmektedir. Ona göre, aynı zamanda sosyokültürel bir olgu olan müziğin, özneler arası alanda dolaşımda olan bir kodlar sistemi olarak düşünüldügünde, belirli bir epistemolojik temele sahip olması gerekir. Ve bu temeli ortaya çıkarmak müzikal analizin gözden kaçırmaması gereken temel ödevlerinden biri olmalıdır. "Müzik hakkında konuşmak" düşüncesini müziğin epistemolojik temelleri bakımından ele almamız ve bu fikri bu bakımdan revize etmemiz gerekir. Baroni'nin deyimiyle "kuramsal tartışma günümüzde artık kompozisyon ya da icra pratiğine yaslanmaktan ziyade, müzikal dilin yapısını ve kuramların tanımladığı üst-dilleri tartışmak demek olmalıdır" (Baroni 1983: 176).

Baroni'ye göre bir müzik metnini analiz etmenin ya da tanımlamanın her zaman varsaydığı kimi kuramsal temeller vardır. Üstü kapalı ya da bilinçsiz bir biçimde yapılıyor olsa bile, her analiz tartışması bir dizi kuramsal düşünceye kaçınılmaz bir biçimde referans verir ya da gönderme yapar. Yazarın bunun açıkça farkında olmasa gerekmez: "Analitik ya da tanımsal durumlar her zaman açıkça sunulmaz; müzik tartışmasında denenmeden alınmış birçok kavram bulunabilir. Eleștiri ve analizde böylesi sorunlar bu tartışmaların pratik işe yararlıklarını değil, gizli kuramsal varsayımlarını yansıtır" (Baroni1983: 175-176). Baroni'nin önerisi, 
böylesi temel varsayımları açığa çıkarmak ve onların üzerine giderek açık birer tanım sahibi olmalarını talep etmektir.

Baroni'ye göre, insan bilimlerinde doğa bilimlerinden farklı olarak, nesnelerin kültürel uzlaşımlara gönderimde bulunduklarını hesaba katmak gerekir. Dilbilim söz konusu olduğunda seslerin fiziksel özelliklerinin ikincil öneme sahip olması gibi, müzik kuramı söz konusu olduğunda da böylesi bir ayrımı kullanmak mümkün ve gereklidir. Müziğin bir iletişim aracı olarak ele alınması sürecinde notaları saymak, matematiksel kesinliklere ulaşmak, formüller uygulamak ya da figürlerin uzun birer listesini oluşturmak yeterli değildir. Şayet müziğin bir dil olarak görülebileceği söylenecekse, onun en azından iki ayrı düzlemde ele alınması gerekecektir: "İfade düzlemi”, yani işitilebilir yapı ve "içerik düzlemi”, yani anlamsal yapı. Baroni'ye göre bu iki düzlemin özü itibariyle birbirleri ile imleme (sign) ve gönderimde bulunma (refer) ilişkisi içinde olduğu söylenebilir. Bu bakımdan bir müzikal kodun varlığından söz edilebilir, ancak bu kodun konuşulan bir dilden farklı olarak tamama ermemiş bir kod olarak ve bir estetik iletişim sistemi olarak kabul edilmesi gerekir (Baroni 1983: 180-181).

Baroni müzikal dilbilgisinin olanaklarını sorgularken mikro-yapı ve makroyapı gibi iki yapı düzlemini ayırır. Makro-yapı söz konusu olduğunda, Baroni, bir bütün olarak eseri yapı olarak kabul edebileceğimizi ve eserin bileşenleri olarak ifadelerin birbirleri ile bağlantılarını ifadenin son sesleri üzerinden inceleyebileceğimizi öne sürer (Baroni 1983: 190-191). Mikro-yapı söz konusu olduğunda ise, "Avrupa sanat müziğini" takip ederek tampere sisteminin perde aralıklarını bütünün temel birimleri olarak ele alabileceğimizi savunur. Ona göre, bu temelden yola çlkarak bir dilbilgisi kurallar sistemi kurmak için beş kategori oluşturmamız yeterlidir. Bu kategoriler (1) diatonik dizide ölçülmüş ses aralığı; (2) nota süresi; (3) ölçü içindeki olası pozisyonların bir kataloğuna göre verili olan metrik pozisyon; (4) 7 diatonik basamağın biri olarak derece ve (5) tonalite (Baroni 1983: 186-187). 
Baroni'nin kuramı müzikal kodu yazı düzleminde ele alır ve bu yönüyle, kullanmakta olduğu dil modelini daha baștan bir temsil ilişkisiyle belirleyerek bir kuramsal varsayımı üstlenir. İkinci olarak, eserin makro-yapı olarak sunuluyor oluşu, temalar, akımlar ve kanon gibi daha büyük yapıların makro-yapı üzerinde belirleyiciliğinin nasıl anlaşılması gerektiği sorununu gündeme getirir.

Bir diğer kuramcı olan Jean-Jacques Nattiezise dilbilimde biçim ve anlam arasındaki sınırı tanımlamanın gittikçe zorlaştığını belirterek fonem sorununa, kendi deyimiyle "anlamdan yoksun unsuru ayırma"nın gerekliliğine dikkat çekmektedir. Bu noktada Nattiez’ye göre müzik, kendi özgün bölünemez unsuruna, nota unsuruna sahip olmakla görsel sanatlar göstergebiliminden ayrılmaktadır (Nattiez 1973: 53).

Nattiez temel birim konusunda iki olası görüşü bize aktarır. Bunlardan ilki kimi işlevselcilerin ve glossematik okulların yaptığı gibi unsurları insan iletişimindeki rolleri üzerinden tanımlamaktır. Bir diğeri ise N. Ruwet'nin yaptığı gibi bu unsurları anlamla ilişkisinden ziyade "tekrar etme" ile ilişkilendirmektir (Ruwet 1987: 11-36). Bu durumda ifade/cümle, hücre (cellule), figür, motif, periyot ve tema gibi unsurları, Nattiez'ye göre, başı ve sonu ayırt edilebilir şekilde tanımlayabilmek gerekir. Motif ya da tema unsurlarından başlamak şimdiye dek literatürün "hastalıklı bir şekilde" gelişmiş olmasına neden olmuştur; bu unsurları sezgisel anlamları ile kullanarak ilerlemeye çalışmak işe yaramaktadır, ancak doğru olmayan bir yolla işe yaramaktadır (Nattiez 1973: 54-62).

Nattiez’ye göre müzikal göstergebilim, birimlerin kombinasyonundan bir eserin ya da bir eserler dizisinin nasıl ortaya çıktığını gösterebilecek bir söz dağarcığı ve bir biçim icat etmelidir. Müzikal analizin bilimsel standartlarda yapılması, ona göre, unsurların açık ve tekrarlanabilir bir biçimde birimlerine ayrılmasını gerektirir (Nattiez 1973: 64). Ancak Nattiez bunu yapıdan yola çıkarak, tümdengelimsel bir yolla, Saussurecü dilbilimsel modelin taksonomisini müzik olgusuna uygulamayı deneyerek yapmayı önerir ve dil-söz ikiliği tartışmasına ek 
olarak, tema olgusundan ifade/cümle olgusuna inene kadar tümdengelimsel bir yol takip eder.

Nattiez'nin ifade/cümle unsurunu en temel anlamsal birim olarak sunması Baroni'nin "gizli kuramsal varsayımlar" hatırlatmasının iyi bir örneğini oluşturmaktadır, zira Nattiez'nin eksik bıraktığı üzere, en temel birimin ne olduğunun gerekçeleriyle tartışılabilir olması gerekir. Bu birimin ne olduğu, daha küçük birimlere bölünemeyecek bir birimle karşılaşma ya da en küçük birimin ortaya çıkışını anlamaya çalışma yoluyla açığa kavuşturulabilir. Aradığımız olgu iki unsurun, müzikal gösteren ve müzikal gösterilen unsurlarının eklemli hali ise, bu iki unsurun eklemliliğinin sınırlarını, eklemlenme/artikülasyon olgusunun kendisini ölçüt alarak incelemek de olası bir yol olmalıdır. Zira Molino'nun da dikkat çektiği üzere, eklemlenme olgusunu inceleyebileceğimiz bir yol izlemeden böyle bir varsayımı üstlenmemek gerekir (Molino 1990: 142).

Bir sonraki bölümde müzikal eklemlenme olgusunun ortaya çıkış ve yok oluş sürecini iki yönlü incelemeye çalışan basit bir uygulama örneği sunulacaktır. Bunlardan ilki "bütünden parçaya" olarak nitelenebilecek, yapının kendisinden hareket eden bir yol olacaktır. İkinci yol ise tam tersine, temel birimin ortaya çıkışını, yani gösteren ile gösterilenin eklemlenme olgusunu arayan, "parçadan bütüne" olarak nitelenebilecek bir yoldur. Benzer bir yöntem N. Ruwet tarafından 1966 yılında sunulmuşsa da burada farklı olarak fenomenolojik yöntem izlenecektir.

\section{Temel Birimi Bulmaya Yönelik İki Alternatif Yol}

Ruwet 1966 tarihli çığır açıcı makalesinde, her gösterge sisteminde kod ve mesaj arasındaki ilişkinin iki ayrı yolla tanımlanabileceğini hatırlatır: Mesajdan koda doğru ya da tam tersine, koddan mesaja doğru bir işlem sürdürerek, birinden yola çıkıp diğerini anlamak. Birinci seçenek, Levi-Strauss'un mitler ile ilgili çalışmasında yaptığı gibi, mesajdan koda doğru analitik bir izleği takip eder; mesajı 
analiz ederek ve yapısöküme uğratarak birimleri, birim sınıflarını ve bunların kod oluşturmak için takip ettikleri birleşme kurallarını ortaya çıkarır (Levi-Strauss Kasım 2012: 297-333). İkinci seçenekte ise en soyut ve genel unsurlardan yola çıkarak, sentetik bir izlekle belirli mesajlar ya da dilbilgisel cümleler oluşturulabilir. Ruwet'ye göre ikinci yol birincinin ayna yansıması gibidir, onun sağlamasında kullanılabilir ve yeni mesajlar bu yolla oluşturulabilir (Ruwet 1987: 11-12).

Ruwet bu iki yöntemin müzikolojiye uygulandığında "tepeden dibe doğru” ya da "dipten tepeye doğru" olarak düşünülebileceğini dile getirir ve buradaki en önemli riskin, sentetik izleğin kural belirleyici bir sisteme dönüşmesi olduğunu hatırlatır. Diğer bir deyişle, koddan yola çıkıp dilbilgisel olarak "doğru" olan belirli cümleler ve mesajlar oluşturarak bunların "kural" halinde sunulması gibi bir risk söz konusudur. Ancak Ruwet'ye göre esas ciddi sorun, tüm bu işlemi yaparken örtük olarak kabul edilen veya varsayılan ölçütlerin açıkça dile getirilmemesidir. Oysa kökensel anlamda "analitik" bir bilimsel işlemin bu ölçütü sağlamamak gibi bir lüksü olmamalıdır (Ruwet 1987: 12-14).

Ruwet temel unsurları kategorize etmek için, parametrik ve parametrikolmayan iki unsur tipi önerir: Parametrik unsurlar ya hafif-güçlü, uzak-yakın gibi karşıtlık içinde düşünülebilecek unsurları ve eser süresi, tempo veya tını gibi bölünemez unsurları kapsar. Aksine, parametrik-olmayan unsurlar, karşıtlık içinde düşünülemeyecek olan yoğunluk gibi unsurları kapsar (Ruwet 1987: 16). Müzik teknolojileri alanında günümüzde varılan noktayı düşündüğümüzde bu ayrımların güncelliğini koruduğunu söylemek mümkün olmasa da, Ruwet'nin "parametrik unsur" ve "karşıtlık unsurları" analizde halen işlevsel olabilecek kategorilerdir.

Ruwet'nin iki yönlü yöntemi, eklemlenme olgusunun hangi aşamada ortaya çıktığını ve tam tersine hangi aşamada bölümleme (segmentation) yoluyla ortadan kaldırıldığını izleme olanağı sunar.Benzer şekilde, analizin teksesli düzlemde, sadece süre ve ses aralığı ölçütlerine göre alınmış olması da Ruwet'nin yönteminde 
takip edilebilirliği sağlayan diğer bir avantajdır; daha büyük birimler kurulmasını gerektirmeyecek kadar az değişken içerir ve her iki ölçüt de parametrik ölçütlerdir (Ruwet 1987: 16-17).

Ruwet'nin "tepeden" nitelemesine göre, elimizdeki bilgi nesnesine tepeden bakınca ne görüyor olmamız gerekir? ÖncelikleBaroni'nin hatırlattı̆̆ı gibi, Klasik Batı Müziği tampere sistemine göre ayrılmış 12 yarım seslik oktav bütünlüğünü temele alır; ancak bir diğer önemli husus Baroni'nin dikkatinden kaçmıştır: Tampere bölümlemesi, ses fiziği açısından seslerin doğal bölümlenmesiyle tam olarak örtüşmediği için, daha baştan bir uzlaşımsal düzlemle karşı karşıya olduğumuzu kabul etmek gerekir (Zeren 2008: 77; Zeren 2010: 269-278; Baroni 1983: 187). İkinci uzlaşımsal düzlem, bu seslerden birinin anlamın kurucu sabiti, yani ton/tonik olarak seçilmesi ve diğer seslerin onun etrafında uyumlu/consonant ya da uyumsuz/dissonant nitelemelerinin belirlediği sınır içine örgütlenecek şekilde yerleştirilmesidir. Toniğin çıkıcı yönde üçüncü, dördüncü ve beşinci dereceleri olan mediant, subdominant ve dominant, akor kurulumunda temel birimlerdir ve bu durumun bir taraftan doğuşkanlar olgusu, diğer taraftan teslis inancı ile tarihsel ve fiziksel bağları vardır. Öte yandan akorların birbiriyle bağlantısallığı açısından armonik çözülüm olgusu, akorların durucu-yürüyücü özellikleri üzerinden ilişkiselliğine bağlı kadans olgusu ve daha soyut birer olgu olarak müzikal ifade ve tema olguları Klasik Batı Müziğinin Saussurecü anlamda“bakış açısının” temel bileşenleri olarak eldeki sistemi yapılandırır.

Klasik Batı Müziği bir sistem olarak düşünüldügünde, onun bir dil mi yoksa daha büyük bir dilin söylemlerinden biri mi olduğu sorusu kaçınılmaz olarak gündeme gelecektir. Diğer müzik gelenekleriyle aynı kümede toplandığında ya da akımlara, eser türlerine ve temalara bölündüğünde ise sorunun meşruiyeti daha aşikâr bir hal alır. Ancak belirli bir eser ya da eserin bir partisyonu söz konusu olduğunda bir "mesaj" ya da mesajlar toplamı ile karşı karşıya olduğumuzu söylemek oldukça kolaydır. Yöntemi devam ettirecek olursak, Baroni ve Nattiez'nin 
önerdiği gibi, bir tema, motif, figür ya da daha küçük birimlerle karşılaşabiliriz (Baroni 1983: 188-190). Bu birimler akorlardan veya daha küçük birimler olan ölçülü belirli tikel seslerden oluşur. Bu noktada şayet ele aldığımız ses bir oktavın 12 sesinden biri olacaksa, onun dizinin kaçıncı derecesi olduğunu anlamamız için ton ile zorunlu bir ilişki kurmamız gerekecektir. Bu durumda, ele aldığımız sesin kendisinden ziyade tonun uzlaşımsal bir yolla elde ettiği kavramsal içeriğe gönderim söz konusudur. Ton unsuru, şu halde“gösterilen” olarak bu kavramsal içeriğe, tampere sisteminin 12 sesinden birini "gösteren" olarak seçmek suretiyle eklemlenir. Böylece, tonalite Klasik Batı Müziği için tek seçenek olmasa da, tonal müzik için ton unsuru müzikal bir gösteren ile bir kavramsal içeriğin eklemliliğine rastladığımız en küçük birim sayılabilir. Dahası o, dizinin anlamsal sistemi için kurucu niteliğe sahip, hiyerarşik üstünlüğe sahip bir göstergedir; kromatik ya da tonal diğer sesler, kavramsal içeriğini ona gönderimde bulunarak kazanır.

Klasik Batı Müziği bağlamından çıkmayı göze alarak bir adım daha atabilir ve öncelikle tonaliteyi, sonra tampere bölümlemesini paranteze alabiliriz. Şüphesiz ki fiziksel bir olgu olarak ses olayının kendisi ortadan kalkmayacaktır, ancak sesin müzikal amaçlarla kullanımını, yani bir gösterilen olarak "müzik" kavramsal içeriğinin, bir gösteren ile eklemli hale geldiğinin ilan edilmesini beklememiz gerekir. Diğer bir deyişle, gerçekleşmekte olanın "müzik" olduğunu, onun zamansal başlangıcını müjdeleyerek bize işaret eden bir gösterene ihtiyacımız olacaktır. Bu ölçüt her türlü icra/performans etkinliğinin işaretlenmesi için geçerli olabilecekken, müzik için özsel bir işleve sahiptir. Zira sadece etkinliğin ya da eserin başını ve sonunu işaretlemekten ziyade, süreyi her koşulda ölçülü ve metrik birimlere bölerek ritim unsurunu ortaya çıkarmaya yarayacaktır. Sürenin bölümlenmesi olarak ritim olgusunun, bu bakımdan bağlamın kısıtlamalarını aşan, kökensel anlamda kurucu bir işlevi olduğu söylenebilir.

Temel birim arayışında ikinci bir olası yol, eklemlenme olgusunun ortaya çıkışını parçadan bütünedoğru ya da dipten tepeye doğruaramaya çalışmaktır. Bu 
noktada, türsel ve yapısal hiçbir özelliğini bilmediğimiz bir eserin icrası ile karşı karşıya olduğumuzu varsayalım. Eserin orada bulunup bulunmadığını anlamanın yolu, öncelikle uzlaşımsal düzlemin kendi varlığını belirli kılmasını gerektirecektir (Nattiez 1990: 43; krş. Cage 1991). Ancak, tesadüfen orada bulunan ölçülü bir sesin eser kompozisyonunda bir işlevi olup olmadığından emin olamayız; bu ses Gettier probleminde olduğu gibi, yanlış kanımızı destekleyecek yönde, tesadüfen orada bulunuyor olabilir. $\mathrm{Bu}$ ihtimalden kaçınmak için estetik izolasyon unsurunu kullanmamız gerekecek, yani eserin başını ve sonunu işaretlemek zorunda kalacağız. Örneğin bir orkestra şefinin bizim yerimize bunu yaptığını varsayalım. Orkestra şefinin işaretleme işlemini müzikal eklemlenme olgusunu kullanmadan, yani bir müzikal gösterene başvurmadan da icra etmesi oldukça mümkündür; metronom belirlenir ve el işareti ile eserin girişi müjdelenir. Böylece eseri henüz duymamış olsak da onun örneğin 3/4'lük bir ritimde bestelenmiş olduğunu öğrenmiş oluruz. Şu halde, ölçü başlarının hala ses kullanılmadan işaretlenmesi mümkündür.

Takip ettiğimiz ikinci yolda, herhangi bir müzikal gösterge kullanmadan, yani bir kavramsal içerik ile bir müzikal gösterenin eklemlenmesine rastlamadan estetik sürecin gerçekleştiği düşünülebilir; ancak buradaki temsil ilişkisi ikincil düzey bir temsil ilişkisidir: Gösteren olarak el hareketinin gösterileni, daha önceden belirlenmiş bir içerikle birleşik haldedir. Bu noktada sorulabilecek felsefi sorular tüketilmiş sayılmaz, ancak müzikal göstergenin eklemlenme olgusu ile karşılaşabilmek için bir adım daha atmamız gerekir. 0 halde karşılaşacağımız ilk anlamlı ve eklemli ses, kompozisyonel önceliğe sahip olan ritim unsurunu işaretleyen güçlü ve hafif vuruşlar olacaktır. Bu noktada herhangi bir ritim çalgısı kullanılmadan da eserin icra edilebileceği savunulabilirse de, 3/4'lük bir eserin örneğin Türk aksağı ritmiyle icra edilemeyeceği aşikârdır.

Kullanılan ikinci yolda Ruwet'nin sözünü ettiği ses aralığı ve süre ölçütlerinin sağlandığını görmekteyiz. Ortaya çıkan ürünün henüz bir eser olarak 
değerlendirilmesi zor olsa da dört temel ölçüt elimizde sayılacaktır. Bunlar (i) süre, (ii) ses aralığı, (iii) bölümlenme ve bunların birleşimini sağlayan (iv) eklemlenme/artikülasyondur. İşlemin bu noktada "sessiz süre" ve "süresiz sessizlik" gibi unsurlara doğru devam ettirilmesi mümkünse de bu son saylan unsurların analizi ayrı bir felsefi araştırmanın konusudur.

\section{Sonuç}

Yirminci yüzyılda sosyal bilimlerin birçok alanında dilbilimsel modelin uyarlamaları ile karşılaşılmıştır. Saussure ve Peirce'ın göstergebilim anlayışları diğer alanlarda olduğu gibi müzikal göstergebilim alanının tesis edilmesi sürecinde de sıklıkla referans kabul edilmiştir. Molino nota, hücre ya da motif gibi temel nota grupları ve bunların kombinasyonları olmak üzere üç temel müzikal birimler düzlemi olması gerektiğini önermiş ve dil-söz ayrımı ile gönderge sorunsallarını Saussure sonrası tartışmalarla ilişkilendirerek tartışmıştır. Baroni ise müzikal dilin yapısını anlamaya çalışırken müziğin epistemolojik temellerini sorgulamamız gerektiğine dikkat çekmiştir. Ona göre bu noktada en önemli dezavantajlardan biri, müzikal analizin gizli kuramsal varsayımları üstleniyor oluşudur ve tartışmanın temel unsurlarının açık birer tanım sahibi olmalarını talep etmek bu noktada büyük önem arz etmektedir.

Nattiez’ye göre müzik, nota gibi özgün bölünemez bir unsura sahip olmakla görsel sanatlardan daha avantajlı görünüyor olsa da, Nattiez'nin tümdengelimsel yolu takip ederek vardığı temel birimin ifade/cümle olduğuna dikkat çekilmelidir. Benzer bir yol Baroni tarafından da takip edilmiş ve mikro-yapı söz konusu olduğunda temel birimin tampere sisteminin perde aralıkları olması gerektiği öne sürülmüştür. Makro-yapı söz konusu olduğunda ise Baroni de temel birimin ifade olması noktasında Nattiez ile görüş birliği içerisindedir. Bu noktada bir diğer alternatifte, Ruwet'nin "parçadan bütüne" ya da "dipten tepeye" adını verdiği yolu takip ederek ilk anlamlı birimi tespit etmeye çalışma gerekliliği ortaya çıkmaktadır. $\mathrm{Bu}$ yollarla, temel birimin ortaya çıkışı ve ortadan kalkışı ile karşılaşma imkanı 
bulabilmekteyiz. Bu bakımdan iki yol birbirinin sağlaması olarak düşünülmelidir. Ruwet'nin önerdiği iki ayrı yolu aktüel işitme deneyimine ve genel olarak deneye başvurmaksızın fenomenolojik bir yolla uygulamaya çalıștığımızda şu sonuçlara ulaştık: Öncelikle, bütünden parçaya doğru inerken ilk karşımıza çıkanlar, kuramsal tartışmamızın bağlamı dâhilinde Klasik Batı Müziğinin kanonik çatısını oluşturan tampere sistemi ve ses bölümlemesini belirleyen uzlaşımsallık düzlemi olmalıdır. Bu noktada, bu çalışmanın sonuçları, tampere sisteminin uzlaşımsallık aracılığıyla belirleniyor olması hususunda Nattiez ve Baroni'nin çalışmalarından farklılaşmaktadır. İkinci olarak, anlamın kurucu sabiti olarak ton olgusu ile karşılaştık: Akım, tema ve eser türleri gibi daha büyük birimler mevcut olsa da, bu birimler uzlaşımsal ton olgusuna gönderimle kurulan birimlerdir. Klasik Batı Müziği bağlamından çıkmayı göze aldığımızda ise karşılaşabileceğimiz en küçük birim, zamansal olarak sınırlandırılmış bir ses olmalıdır. Bu bakımdan bu yol, bizi, sürenin bölümlenmesi olarak ritim olgusuna ulaştıracaktır.

Parçadan bütüne doğru ilerlerken ise gösteren ve gösterilen arasındaki açık eklemlenme olgusu ile karşılaşmayı beklememiz gerekir. Eserin tonunu ya da başka bir derecesini duyma yoluyla bir eserle karşı karşıya olduğumuzu anlamamız ilkece mümkünse de, ses olgusunu işitmemize gerek kalmadan, sürenin nasıl bölümleneceğini el işaretleri ile gösteren herhangi bir işaretçi kullanarak da müzik eserinin tanınması mümkündür. $\mathrm{Bu}$ durumda, gösterilenin süre bölümlenmesi, gösterenin ise işaretçinin hareketi olması gerekir. Ruwet'nin ifadesiyle bu ilk unsur bölünemez bir "parametrik" unsur olmall, bölünmesi durumunda müzikal anlamın artık ortadan kalktığı gözlenmelidir.

Takip ettiğimiz yolda, deneyim esnasında tesadüfen işitilebilecek bir ölçülü sesin yaratabileceği sorunu bertaraf etmek amaciyla estetik izolasyona başvurulması yöntemsel açıdan gerekli olacaktır. Ancak bu durumda özel olarak bir müzikal deneyimle değil, genel olarak bir estetik deneyimle karşı karşıya olduğumuz bilineceği için henüz bir müzikal göstergenin ortaya çıktığından söz 
etmek mümkün değildir. Bu koşul ancak bir işaretçinin süre bölümlemesini işaret etmesiyle gerçekleşir.

Temel birim arayışında kullanılan her iki yolun sonucunda da ritim olgusuyla karşılaşılmış olması araştırmamızın bağlamında anlamlı olsa da, bir kültürel olgu olarak müziğin gösterdiği çeşitlilik hesaba katıldığında bu sonucun tüketici olmayabileceği dikkate alınmalıdır. Bu bakımdan, varmış olduğumuz sonuçların Klasik Batı Müziği ile kısıtlanmış olduğu özel olarak belirtilmelidir. 


\title{
The Question of Basic Unit in Musical Semiotics in the Context of Classical Western Music
}

\author{
Summary \\ Firat ÍLIM \\ Assist. Prof. Dr \\ Van Yüzüncü Yll University, Faculty of Letters, Department of Philosophy, Van, TR \\ ORCID: 0000-0003-1226-7098 \\ firatilim@yyu.edu.tr
}

After C. Peirce's and F. de Saussure's theories, musical semiotics / semiology emerged relatively later than many disciplines of semiotics / semiology. Although 440 $\mathrm{HZ}$ is mostly accepted as a universal constant for "La / A" and it can be determined objectively, we are still faced with an open question when it comes to signify "music" and the basic unit of music. One of the possible ways of dealing with the problem is to explore it in a phenomenological way, without reference to actual hearing experience and experience in general. In this paper, the basic unit problem will be discussed with a phenomenological method and the articulation phenomenon between the signifier and the signified will be sought in particular. In this regard, after discussing the views of the scholars, two separate paths will be used, which Ruwet calls "from top to bottom" and "from bottom to top".

The basic unit problem, as a problem of musical analysis, and especially of musical semiotics, was first mentioned by J. Molino and N. Ruwet. According to Molino, note is the basic unit in the tonal Western music, and the semiotic existence of the note is guaranteed in the composition, performance and listening processes of note writing. In this case, the unit can exist at three levels: Note, cell and motive; and their combinations. However, according to Molino, the main point to be drawn in any case is that; compared to the linguistic sign, the musical note carries a phenomenon that cannot exist on its own (Molino 1990: 141-142).

The fundamental problem in Molino's theory is not whether we can perform any action with a musical code. In any case, the main question we need to answer must be whether we can follow the same signifier-signified relationship every time. Since we cannot write a C-major chord and argue that it is a D-minor chord, we need to be able to explain systematically if there is a "musical" sign, which is supposed to be the structural unit of music, can be followed and repeated every time.

According to M. Baroni, music, which is also a socio-cultural phenomenon, should have a certain epistemological basis when considered as a system of codes 
circulating in the intersubjective field (Baroni 1983: 176). For Baroni, a musical text in musical analysis always presupposes some theoretical basis. Baroni's suggestion is to uncover such basic assumptions and to go over them to demand to have a clear definition. According to Baroni, it is necessary to take into account that, unlike the natural sciences, objects refer to cultural conventions in the human sciences. If it is to be said that music can be seen as a language, it will have to be considered at least on two separate planes: plane of expression (audible structure) and the plane of content (semantic structure). For Baroni, the two planes can sign each other or refer to each other. In this sense, a musical code is thought to exist, but the code need to be taken as a non-finalized code and a as a system of aesthetic communication (Baroni 1983: 180181).

For Baroni, in terms of macrostructure, we can accept a work of art as a system and analyze phrases of the work in relation to final notes of the phrases (Baroni 1983: 190-191). When it comes to microstructure, we can accept the pitch-classes of the temperament system as the basic units of the corpus by following the traditions of European art-music. According to him, it is sufficient to create five categories to establish a grammatical rules system based on this basis: The categories are (1) pitch, measured on the diatonic scale, (2) note-length; (3) metrical position, assigned according to a catalogue of possible positions within the bar; (4) degree, as one of the seven diatonic steps and (5) tonality (Baroni 1983: 186-187).

Another scholar, Jean-Jacques Nattiez, while comparison between music and language, states the difficulty of determining the limits between form and meaning; and suggests to separate phonemes as "meaningless items". For Nattiez, music differs from visual arts semiotics by having its own unique discretizable element, note. (Nattiez 1973: 53).

For Nattiez, musical semiology should invent a vocabulary and a form that can show how a work or a series of works emerges from the combination of units. For him, musical analyses acquires scientific standards, explicit and repeatable division into units (Nattiez 1973: 64). However Nattiez, by starting from the structure in a deductive way, suggest an application of the taxonomy of the Saussurean linguistic model to music; and follows the deductive way from theme to phrase/sentence, in addition to langue-parole duality.

Nattiez's presentation of the phrase/sentence element as basic semantic unit is a good example of Baroni's reminder of "hidden theoretical assumptions", for as Nattiez lacks, the basic unit question needs to be discussed by the given reasons. What the unit is can be clarified by encountering a unit that cannot be divided into smaller units, or by trying to understand the emergence of the smallest unit. If the phenomenon we are looking for is the articulation of the two elements, the musical signifier and the musical signified, then it should be a possible way to examine the limits of the articulation of these two elements by taking the articulation phenomenon itself as a criterion. Because, as Molino points out, it is necessary not to take over such an assumption without following a path in which we can examine the phenomenon of articulation (Molino 1990: 142). 
In the next section, a simple application example that tries to examine the emergence and disappearance process of the musical articulation phenomenon from two directions will be presented. The first of these will be a path that can be described as "from the whole to the part" and starts from the structure itself. The second way, on the contrary, is a way that can be described as "from the part to the whole", which seeks the emergence of the basic unit, that is, the articulation of the signifier and the signified. Although a similar method was presented by N. Ruwet in 1966, a different phenomenological method will be followed here.

Ruwet recalls in his seminal 1966 article that in every sign system, the relationship between a code and a message can be defined in two different ways: starting from one to understanding the other, by continuing a process from message to code or, conversely, from code to message. Ruwet states that these two methods can be thought of as "from the top to the bottom" or "from the bottom to the top" when applied to musicology.

According to Ruwet's way "from above", what should we see when we look at the object of knowledge we have from above? As Baroni reminds, Classical Western Music is based on the unity of a 12 semi-tone octave separated according to temperament; but there is another important point which lacks: Since the temperament does not fully coincide with the natural division of sounds in terms of musical acoustics, it must be admitted that we are dealing with a conventional plane from the beginning of the experience (Zeren 2008: 77; Zeren 2010: 269-278; Baroni 1983: 187). The second conventional plane appears at the selection of one of these sounds as the constitutive constant of meaning, that is, tone/tonic, and placing the other sounds around it in such a way that they are organized within the boundary determined by the consonants or dissonants. Mediant, subdominant and dominant, the third, fourth and fifth degrees of the tonic in ascending direction, are the basic units in chord formation, and adding resolution, cadence, musical phrase and theme, we have the basic components of the Classical Western Music point of view, in the Saussurean sense.

Continuing the method, we may encounter a theme, motive, figure or smaller units, as Baroni and Nattiez suggest (Baroni 1983: 188-190). These units are made up of chords or smaller units of certain particular measured sounds. At this point, if the sound we are considering will be one of the 12 sounds of an octave, we will have to establish a necessary relationship with the tone in order to understand what degree of scale it is. In this case, it is a reference to the conceptual content that the tone conventionally obtains, rather than the sound itself that we are considering. The tonal element is then articulated to this conceptual content as the "signified" by choosing one of the 12 sounds of the temperament as the "signifier". Thus, although tonality is not the only option for Western Classical Music, "tone" for tonal music can be considered the smallest unit that we come across with the articulation of a musical signifier and a conceptual content. Moreover, it is a sign with hierarchical superiority, constitutive of the semantic system of the scale; other chromatic or tonal sounds acquire their conceptual content by referring to it. 
We can take a step further, leave the Western Classical Music context and bracket the tonality first, and then the temperament. Undoubtedly, the sound event itself as a physical phenomenon will not disappear, but we should wait for the use of sound for musical purposes, that is, the announcement that the conceptual content of "music" as a signified becomes articulated with a signifier. In other words, we will need a signifier that sign us what is happening is "music", by heralding its temporal beginning. While this criterion may be valid for marking any performance, it has an essential function for music. Because, rather than just marking the beginning and the end of the activity or work, it will help to reveal the rhythm element by dividing the duration into measured and metric units. It can be said that the phenomenon of rhythm, as the division of duration, has a constitutive function in this respect.

A second possible way in the search for the basic unit is to try to look for the emergence of the phenomenon of articulation from the part to the whole or from the bottom to the top. At this point, we can assume that we are faced with the performance of a work whose generic and structural features is not known for the given moment. To understand whether the work is there or not, even for the most radical example, "4'33" of Cage, the conventional plane will be firstly required to make its existence certain. For this purpose we will have to use the element of aesthetic isolation, that is, we will have to mark the beginning and the end of the work. For example, a conductor may do this for us. It is quite possible for the conductor to perform the marking process without using a musical articulation phenomenon, that is, without resorting to a musical signifier. The metronome is determined and the beginning of the work is heralded with a hand signal. Thus, although the piece is not heard yet, a listener may learn that it was composed, for example, in a 3/4 rhythm. Thus, it is still possible to mark the beginning of bars without using any sound.

In the second way we follow, it can be thought that the aesthetic process takes place without using any musical sign, that is, without encountering the articulation of a conceptual content and a musical signifier; however, the representation here is still a secondary representation: The signifier of the hand gesture as the signifier is combined with a predetermined content. At this point, we still may have possible philosophical questions, however we need to take one more step in order to encounter the phenomenon of articulation of the musical sign. Then the first meaningful and articulated sound will be stressed/strong and unstressed/weak beats marking the rhythm element, which should have the compositional priority. At this point, although it can be argued that the piece can be performed without using any rhythm instrument, it is obvious that a $3 / 4$ piece cannot be performed, for example, with a $5 / 4$.

In the second path used, although it is difficult to evaluate the resulting product as a work, four basic criteria mentioned by Ruwet are met. These are: (1) duration, (2) pitch, (3) segmentation and (4) articulation. 


\section{KAYNAKÇA | REFERENCES}

Baroni, M. (1983). The Concept of Musical Grammar. Musical Analysis, 2, (2), 175-208.

Barthes, R. (2009). Göstergebilimsel Serüven (çev. M. Rifat ve S. Rifat). İstanbul: YKY.

Cage, J. (1991). 4'33", The Sound Corporation. Erişim Tarihi: 16 Nisan, 2021, (https://open.spotify.com/track/2bNCdW4rLnCTzgqUXTTD01?si=Wd0qZslFTWUhB3mADrVnQ).

Derrida, J. (1994). Göstergebilim ve Gramatoloji: JacquesDerrida ile Julia Kristeva Arasında Söyleși (çev. T. Akşin). İstanbul: AFA Yayınları.

Fışkın, Ü. (2018). Sistematik Müzikolojide 20. Yüzyıl Analiz Yöntemleri. Avrasya Sosyal ve Ekonomi Araştırmaları Dergisi, 5 (12), 281-314.

İlim, F. (2019). İki Göstergebilim Kuramı Açısından Nattiez'in Müzikal Göstergebilim Kuramı ve Genel Olarak Bir Müzikal Göstergebilimin İmkânı. I. Uluslararası Müzikte Algı Sempozyumu Tam Metin Bildiri Kitabı (ed. Eren Özek, ss. 57-63). İstanbul: İstanbul Teknik Üniversitesi Yayın Evi.

Levi-Strauss, C. (2012). Yapısal Antropoloji (çev. A. Kahiloğulları). Ankara: İmge Kitabevi.

Molino, J. (1990). Musical Fact and the Semiology of Music (trans. by F. A. Underwood). Music Analysis, 9 (2), 105-156.

Nattiez, J. J. (1973). Linguistics: A New Approachfor Musical Analysis. International Review of theAesthetics and Sociology of Music, 4(1), 51-68.

Nattiez, J. J. (1990). Music and Discourse: Toward a Semiology of Music (trans. by C. Abbate). New Jersey: Princeton University Press.

Peirce, C. S. (1986).Writings of Charles S. Peirce: A Chronological Edition, Volume 3 - 1872-1878 (ed. by C. J. W. Kloesel). Indianapolis: Indiana University Press.

Peirce, C. S. (1998). The Essential Peirce: Selected Philosophical Writings, Volume 2 - 1893-1913 (ed. by the Peirce Edition Project). Bloomington: Indiana University Press. 11-36.

Ruwet, N. (1987). Methods of Analysis in Musicology. Music Analysis, 6, 1/2,

Saussure, F. de (1998). Genel Dilbilim Dersleri (çev. B. Vardar). İstanbul: Multilingua Yayınları. 
İlim, F. Klasik Batı Müziği Bağlamında Müzikal Göstergebilimde Temel Birim Sorunsalı. Kaygi, 20 (2), 2021, 478-501. Yayınlarl.

Saussure, F. de (2014). Genel Dilbilim Yazıları (çev. S. Kılıç). İstanbul: İthaki

Zeren, A. (2008). Müzikte Ses Sistemleri. İstanbul: Pan Yayıncılık.

Zeren, A. (2010). Müzik Fiziği. İstanbul: Pan Yayıncılık. 